\title{
Immune Evasion by Rabies Viruses through the Maintenance of Blood-Brain Barrier Integrity.
}

\author{
Anirban Roy \\ Thomas Jefferson University \\ Douglas C. Hooper \\ Thomas Jefferson University
}

Follow this and additional works at: https://jdc.jefferson.edu/cbfp

Part of the Amino Acids, Peptides, and Proteins Commons, Biological Phenomena, Cell Phenomena, and Immunity Commons, Medical Immunology Commons, Medical Neurobiology Commons, and the Virus Diseases Commons

Let us know how access to this document benefits you

\section{Recommended Citation}

Roy, Anirban and Hooper, Douglas C., "Immune Evasion by Rabies Viruses through the Maintenance of Blood-Brain Barrier Integrity." (2008). Department of Cancer Biology Faculty Papers. Paper 19.

https://jdc.jefferson.edu/cbfp/19

This Article is brought to you for free and open access by the Jefferson Digital Commons. The Jefferson Digital Commons is a service of Thomas Jefferson University's Center for Teaching and Learning (CTL). The Commons is a showcase for Jefferson books and journals, peer-reviewed scholarly publications, unique historical collections from the University archives, and teaching tools. The Jefferson Digital Commons allows researchers and interested readers anywhere in the world to learn about and keep up to date with Jefferson scholarship. This article has been accepted for inclusion in Department of Cancer Biology Faculty Papers by an authorized administrator of the Jefferson Digital Commons. For more information, please contact: JeffersonDigitalCommons@jefferson.edu. 
Integrity

*Address correspondence to:

D. Craig Hooper, Ph.D. 1020 Locust St., JAH 454, Philadelphia, PA 19107-6799. 


\section{ABSTRACT}

The attenuated rabies virus (RV) strain Challenge Virus Standard (CVS)-F3 and a

27 highly pathogenic strain associated with the silver-haired bats (SHBRV) can both be cleared

28 from the central nervous system (CNS) tissues by appropriate anti-viral immune mechanisms

29 if the effectors are provided access across the blood-brain barrier (BBB). In the case of

30 SHBRV infection anti-viral immunity develops normally in the periphery but fails to open the

31 BBB, generally resulting in a lethal outcome. To determine whether or not an absence in the

32 CNS targeted immune response is associated with the infection with other pathogenic RV

33 strains we have assessed the development of immunity, BBB permeability and immune cell

34 infiltration into the CNS tissues of mice infected with a variety of RV strains including the

35 dog variants responsible for the majority of human rabies cases. We demonstrate that the

36 lethal outcomes of infection with a variety of known pathogenic RV strains are indeed

37 associated with the inability to deliver immune effectors across the BBB. Survival from

38 infection with certain of these viruses is improved in mice prone to CNS inflammation. The

39 results suggest that competition between the activity of the immune effectors reaching CNS

40 tissues and the inherent pathological attributes of the virus dictates the outcome and that

41 intervention to deliver RV-specific immune effectors into CNS tissues may have general 42 therapeutic value in rabies.

43 


\section{INTRODUCTION}

46

47

Rabies has been known for centuries as a deadly neurological disease of both humans and animals. The causative agent belongs to a group of antigenically related viruses named after the disease, the rabies viruses $(\mathrm{RV})$. RV strains varying in their genotypes and pathogenicity can be found associated with diverse reservoir species in different geographic locations (Kissi et al., 1995). Each RV strain is associated with a particular natural host species, usually canines and other small carnivores, such as raccoons and skunks as well as bats (Baer et al., 1990). RV strains associated with dogs are the major cause of human rabies worldwide due to prevalence of the virus in developing countries, while an RV strain associated with silver-haired bat (SHBRV) is responsible for most of the endogenous human rabies cases in the United States and Canada (Messenger et al., 2003).

While rabies is generally fatal once the early clinical signs of the disease appear, prompt treatment measures that include wound cleansing and passive administration of RVneutralizing antibodies together with active immunization can prevent development of the disease in an individual exposed to the virus (Fu, 1997). This approach, called post-exposure prophylaxis (PEP), fails to protect an infected individual once neurological signs are apparent (CDC MMWR, 1999). Since neurological signs are indicative of virus replication in the central nervous system (CNS) tissues, it is generally considered to be impossible to clear the virus and save a RV infected individual once RV has spread to the brain from its peripheral site of entry. However, this is not always the case. In a well-documented recent example, a rabies patient who developed evidence of antiviral immunity recovered despite developing severe neurological signs (Willoughby et al., 2005). There is also historical evidence of individuals surviving likely infections with the virus (Gremliza, 1953; Hattwick et al, 1972) as 
68 well as laboratory evidence that RV can be cleared from the CNS tissues if appropriate

69 immune mechanisms develop (Jackson et al., 1989). We have recently elucidated several of

70 the processes required to clear the attenuated RV strain Challenge Virus Standard (CVS)-F3

71 from the CNS (Phares et al., 2006). These include the development of an innate immune

72 response in the CNS tissues and adaptive RV-specific immunity in the peripheral lymphoid

73 organs as well as the infiltration of immune effectors across the blood-brain barrier (BBB)

74 (Phares et al., 2006). The latter is associated with increased BBB permeability to fluid phase

75 markers primarily in the cerebellum of the infected mice (Phares et al., 2006). We have

76 determined that the BBB remains intact and immune cells do not enter the CNS tissues in

77 animals infected with SHBRV (Roy et al., 2007). Consequently, the virus is not cleared and

78 SHBRV-infected animals die of rabies (Roy et al., 2007). Increasing BBB permeability in

79 SHBRV infected animals through the induction of an autoimmune CNS inflammatory

80 response facilitates immune cell entry into the infected CNS tissues and promotes virus

81 clearance thereby preventing the lethal outcome of the infection (Roy and Hooper, 2007).

82 White blood cells and virus specific antibodies was also found to accumulate in the CSF in a

83 patient who survived clinical rabies (Willoughby et al., 2005).

84 Unlike classical rabies, which results from the bite of an infected dog an incident

85 causing infection with SHBRV often goes unnoticed (Jackson and Fenton, 2001; CDC

86 MMWR, 1999, 2007), leading to speculation that these variants may have unique attributes,

87 possibly including the capacity to evade immune clearance. Alternatively, all pathogenic RV

88 strains may interfere with antiviral immune mechanisms at some stage of the infection, an

89 attribute that would explain the failure of PEP later in the disease. To distinguish between 
90 these alternatives we have assessed BBB function and immune cell invasion into the CNS

91 tissues of mice infected with a variety of RV strains. 
92 MATERIALS AND METHODS

93 Animals and virus.

$94129 / \mathrm{SvEv}$ mice were obtained from the in-house breeding colony at Thomas Jefferson

95 University and PLSJLF1/J (PLSJL) mice were purchased from Jackson Laboratories (Bar

96 harbor, ME). Eight to 10 -week old mice ( $\mathrm{n} \geq 10$ per group) were infected via intra-dermal

97 (ID) route in the ear as previously described (Roy et al., 2007). The inoculation dose used and

98 a brief description of each RV strain studied are presented in Table 1 . The doses for the

99 pathogenic $\mathrm{RV}$ strains were approximately $10 \times \mathrm{LD}_{50}$ (ID) in mouse. Cell culture adapted

100 strains that are not lethal for immunocompetent animals were administered at $10^{5}$ focus

101 forming units, an amount that is known to cause CNS infection for CVS-F3 (Phares et al.,

102 2006). All procedures were carried out according to the protocols approved by the

103 Institutional Animal Care and Use Committee of Thomas Jefferson University.

104

105 Tissue collection.

106 Mice were anesthetized and the thoracic cavity was surgically opened. Cardiac blood 107 was collected and mice were transcardially perfused with $15 \mathrm{~mL}$ of PBS supplemented with

$1081 \mathrm{U} / \mathrm{mL}$ Heparin followed by $15 \mathrm{~mL}$ of PBS. Brains were collected and the cerebral cortex and 109 the cerebellum were separated. Tissues were snap frozen in liquid nitrogen and stored at $110 \quad 80^{\circ} \mathrm{C}$ until further use.

111

$112 \quad \boldsymbol{R T}$-PCR.

113 As an indicator of virus replication, RV nucleoprotein-specific mRNA levels were 114 measured in the CNS tissues from infected mice by the reverse transcriptase-polymerase 
115 chain reaction (RT-PCR) technique. Briefly, total RNA was isolated from the snap frozen

116 brain tissues of RV-infected and uninfected control mice using the Qiagen RNeasy Kit

117 (Valencia, CA) as previously described (Phares et al., 2006). cDNAs were synthesized from

118 mRNA by reverse transcription using oligo (dT) as primer. Approiximately $100 \mathrm{ng}$ of cDNA

119 was subjected to PCR amplification using primers specific for a segment of nucleoprotein

120 gene that is largely conserved among all of the virus strains used in the current study. The

121 gene for the house-keeping ribosomal protein L-13 was quantified in each sample to ensure

122 that the quantities of cDNA used for PCR are almost equal in all samples. The nucleotide

123 sequences of the primers used for PCR are: forward primer for RV nucleoprotein gene, 5'-TA

124 CAATGGATGCCGACAAGA -3'; reverse primer for RV nucleoprotein gene, 5'-AAAGGG

125 GCTGTCTCGAAAAT-3'; forward primer for L-13, 5'-TTCCACAAGGATTGGCAGCA-3';

126 and reverse primer for L-13, 5'-TGCTCGGATTGCCAAAGAGT-3'. Equal amounts of the

127 PCR products were subjected to gel electrophoresis using $1 \%$ agarose gel and bands of

128 amplified DNA were visualized under UV light and photographed using a gel-documentation

129 system (Bio-Rad).

130

\section{Quantitative Real Time-PCR}

132 The levels of mRNAs specific for TNF- $\alpha$, IL-6, CD4, CD19 and $\kappa$-light chain genes

133 were measured in cDNA samples by quantitative real-time PCR (QRT-PCR) as previously

134 described, using TaqMan PCR reagents (Applied Biosystems, Foster City, CA), gene-specific

135 primers and probes, synthetic gene standards, and a Bio-Rad iCycler iQ Real Time Detection

136 System (Hercules, CA) (Phares et al., 2006). In each sample, the mRNA copy numbers of a

137 particular gene were normalized to the mRNA copy number of the housekeeping gene L13. 
138 Levels of gene expression in a test sample are presented as the fold increase over that detected

139 in uninfected controls using the formula: $\mathrm{n}$-fold increase $=$ [mRNA copy numbers of a

140 particular gene in a RV-infected sample/ mRNA copy numbers of L13 in that sample] /

141 average of [mRNA copy numbers of that particular gene in an uninfected mouse sample /

142 mRNA copy numbers of L13 in that sample]. The sequences of the primers and probes used

143 for quantitative PCR have been previously detailed (Phares et al., 2006).

$145 \quad$ Measurement of serum antibody titers.

146 Levels of RV-specific total immunoglobulin-gamma ( $\operatorname{IgG})$ in sera from uninfected and 147 RV-infected mice were measured by Enzyme Linked Immunosorbent Assay (ELISA) as 148 described previously (Roy et al., 2007). Briefly, serially diluted sera samples were incubated 149 at room temperature in 96-well plates (Nalge Nunc International, Rochester, NY) coated with

150 UV-inactivated Evelyn-Rokitnicki-Abelseth (ERA) or CVS-F3 $(5 \mu \mathrm{g} / \mathrm{ml})$. Captured antibodies 151 were detected using peroxidase-conjugated anti-mouse $\operatorname{IgG}$ (Sigma). 3, 3, 5, 5' -

152 Tetramethylbenzidine dihydrochloride substrate (Sigma) supplemented with hydrogen 153 peroxide was used for color development. The reaction was terminated by the addition of 2M-

$154 \mathrm{H}_{2} \mathrm{SO}_{4}$ to the wells and the absorbance was measured at $450 \mathrm{~nm}$ in a microplate 155 spectrophotometer (Biotek, Winooski, VT). Antibody titer is calculated as the inverse of the 156 dilution of a serum sample corresponding to the half of the maximum absorbance detected in 157 that sample.

158

159 Assessment of BBB permeability.

160 The extent of BBB permeability was assessed by measuring the amount of a low 161 molecular weight fluorescent marker (Na-fluorescein, molecular weight 376) that leaks from 
162 the circulation into the CNS tissues as previously described (Phares et al., 2006). Briefly,

$163100 \mu \mathrm{l}$ of $10 \%$ solution of Na-fluorescein was injected intra-peritoneally and after 10 minutes

164 mice were anesthetized and transcardially perfused as described above. Snap frozen brains

165 were homogenized in phosphate buffered saline (PBS) and centrifuged. Proteins from the

166 supernatants of the tissue homogenate as well as from serum samples were precipitated with

$16715 \%$ TCA. Fluorescence in the clarified supernatant was measured at excitation and emission

168 wavelengths of $485 \mathrm{~nm}$ and 530nm respectively, using a CytoFluor ${ }^{\mathrm{TM}}$ II fluorimeter (PerSeptive

169 Biosystems, Framingham, MA). The amount of Na-fluorescein in the CNS tissue of each

170 animal was normalized to the level of Na-fluorescein detected in the animal's serum using the

171 formula: Na-fluorescein uptake $=$ [amount of Na-fluorescein detected in the CNS tissue of a

172 mouse/ weight of the tissue]/ amount of Na-fluorescein detected per $\mu \mathrm{L}$ of serum of that

173 mouse. Na-fluorescein uptake into the tissues of each infected animal was divided by the

174 average uptake detected in similar tissues from uninfected control mice and the results are

175 expressed as fold increase.

176

$177 \quad$ Statistical analyses.

178 Results are expressed as the mean \pm the standard error of the mean. The statistical 179 significance of the differences in gene expression and in serum antibody levels between 180 control and infected groups was assessed using the Mann-Whitney test while the $t$-test was 181 used to test the significance of differences in virus nucleoprotein mRNA levels. 


\section{The outcomes of infection with different $R V$ strains differ.}

Ten different RV strains ERA, PM, CVS-F3, DRV-4, Thai-DRV, CVS-N2c, CosRV,

186 SkunkRV, SHBRV and HEP were used in the current study (see Table 1). Groups of

$187129 / \mathrm{SvEv}$ mice were infected via the ID route with each of the RV strains and 8 days

188 following infection, RT-PCR was used to detect the presence of viral nucleoprotein mRNA in

189 the CNS tissues. Viral nucleoprotein message was found in the cortices and the cerebella of

190 all infected mice, with the exception of those that had received the HEP strain (Fig 1). We

191 were unable to detect nucleoprotein message for HEP by RT-PCR in any part of the CNS

192 tissues (olfactory bulbs, cerebral cortex, cerebellum, brain stem and spinal cord) following

193 either ID or intra-nasal administration of HEP (data not shown). However, HEP nucleoprotein

194 mRNA can be detected in cell culture by RT-PCR using the same set of RV specific primers

195 used in this study.

196 Similar groups of infected 129/SvEv mice were monitored for mortality. Mice infected

197 with Thai-DRV, CVS-N2c and SHBRV died around 8-12 days postinfection whereas mice

198 infected with DRV-4, CosRV and SkunkRV died within 12-17 days after infection (Fig 2).

199 Despite the fact that the relatively less pathogenic RV strains, namely ERA, PM and CVS-F3, 200 reached the CNS, mice infected with these strains of RV survived the infection (Fig 2). Mice 201 receiving the HEP RV strain survived without any sign of disease over a 30-day observation 202 period.

203

204 
When RV reaches the CNS tissues it induces the expression of pro-inflammatory 207 cytokines of the innate immune response (Phares et al., 2006; Marquette et al., 1996). A 208 difference in the capacity of different RV strains to induce a CNS innate immunity has been 209 suggested to be associated with the pathogenicity of that virus (Wang et al., 2005). Infection 210 with all of the RV strains that reached the CNS of the $129 / \mathrm{SvEv}$ mice upregulates the 211 expression of genes specific for the pro-inflammatory cytokines TNF- $\alpha$ and IL-6 (Fig 3).

212 Moreover, the expression of these genes is elevated to more or less equivalent extents 213 irrespective of the pathogenicity of the RV strain. Enhanced TNF- $\alpha$ and IL- 6 expression was 214 not seen in the CNS of mice receiving HEP RV, providing support for the likelihood that this 215 particular RV strain is not neuroinvasive.

\section{All $R V$ infections induce strong $R V$-antigen specific antibody response.}

220 infected animals including those receiving HEP, developed an RV-specific IgG response. The

221 serum antibody titers raised by infection with the different viruses were approximately the

222 same with the exception of mice infected with the ERA strain where substantially higher

223 serum antibody titers were seen. Notably, although no evidence of either virus replication or

224 induction of pro-inflammatory genes in the CNS of HEP infected mice was detected, serum

$225 \mathrm{RV}$-specific antibody titers in these mice were equivalent to those of mice infected with other 226 RV strains. 

the CNS.

231 cells, a process that primarily occurs in the cerebellum and, for CVS-F3, involves the activity

232 of CD4 T-cells and B cells (Phares et al., 2006 and 2007). In the absence of the accumulation

233 of these immune effectors in CNS tissues, RV infection is lethal (Roy et al., 2007). Eight days

234 following infection, the expression of the mRNAs specific for CD4, CD19 (phenotypic

235 markers for $\mathrm{T}$ - and $\mathrm{B}$-cells, respectively) and $\mathrm{\kappa}$-light chain (an indicator of antibody

236 production by B-cells) is greatly elevated in the cerebella of mice infected with the less

237 pathogenic ERA, PM and CVS-F3 strains of RV (Fig 5). On the other hand, no significant

238 increase in the expression levels of these genes is seen in the cerebella of mice infected with

239 the pathogenic RV strains DRV-4, Thai-DRV, CVS-N2c, CosRV, SHBRV and SkunkRV 240 (Fig 5).

241 As immune-cell infiltration into the CNS tissues of CVS-F3 infected mice is 242 accompanied by an increase in BBB permeability to the fluid phase marker Na-fluorescein, 243 we next assessed BBB integrity during infection with the different RV strains. The results 244 paralleled the difference in immune cell invasion of CNS tissues between less pathogenic and 245 pathogenic strains of RV. BBB permeability in the cerebellum was indeed significantly 246 enhanced in animals infected with ERA, PM and CVS-F3 strains, but not in animals infected 247 with DRV-4, Thai-DRV, CVS-N2c, CosRV, SHBRV and SkunkRV strains (Fig 6). 
252 strains.

253 We have previously shown that PLSJL mice are somewhat more resistant to lethal 254 infection with SHBRV than 129/SvEv mice (Roy and Hooper, 2007). To test if PLSJL mice 255 are less susceptible to lethal infection with other pathogenic RV strains, groups of $129 / \mathrm{SvEv}$ 256 and PLSJL mice were infected with different RV strains and monitored for clinical signs of 257 rabies and mortality for a period of 30 days post infection. Between 8 to 15 days after 258 infection, 129/SvEv mice infected with all RV strains, except HEP, showed prominent 259 neurological signs of rabies (Table 2). Those infected with the pathogenic DRV-4, Thai-DRV, 260 CVS-N2c, CosRV, SHBRV and SkunkRV strains died within 2-5 days of the appearance of 261 clinical signs, whereas $129 / \mathrm{SvEv}$ mice infected with the less pathogenic ERA, PM and CVS262 F3 strains survived. ERA infected 129/SvEv mice had persistent neurological signs for over 263 10-15 days after first appearance, but nevertheless survived the infection. On the other hand, 264 almost all of the PLSJL mice infected with ERA, PM and CVS-F3 as well as DRV-4, CosRV 265 and SkunkRV survived the infection without any sign of disease (Table 2). Only one mouse in 266 each of the CosRV and Skunk RV infected groups developed neurological signs and both died 267 of rabies. However, the majority of Thai-DRV, CVS-N2c and SHBRV infected PLSJL mice 268 died of rabies after developing neurological signs similar to those appearing in $129 / \mathrm{SvEv}$ mice 269 infected with the same RV strains. The PLSJL mice that survived infection with these viruses 270 did not develop any signs of clinical rabies (Table 2). As an initial probe into why PLSJL 271 mice may survive infections with RV strains that are lethal for $129 / \mathrm{SvEv}$ mice we used 272 quantitative RT-PCR to assess the amounts of virus nucleoprotein message in the CNS of 273 mice infected with two RV strains, CosRV, which is pathogenic in $129 / \mathrm{SvEv}$ mice but non- 
274 pathogenic in PLSJL mice, and CVS-N2c, which is pathogenic in both 129/SvEv and PLSJL 275 mice. At 8 days of infection, the levels of nucleoprotein mRNA of the more pathogenic CVS276 N2c strain were several thousands fold higher in the CNS of both 129/SvEv and PLSJL mice 277 than those of the CosRV strain (Fig 7). However, the nucleoprotein mRNA levels of both 278 viruses were significantly lower in PLSJL mice (Fig 7). Significantly, the only group of mice 279 that survive, PLSJL mice infected with CosRV, exhibits the lowest viral nucleoprotein mRNA 280 levels.

281

282

283 


\section{DISCUSSION}

We have previously shown that while RV-specific immunity develops in the periphery

286 of mice infected with either the attenuated variant CVS-F3 or the highly pathogenic SHBRV,

287 immune effectors are not delivered across the BBB into the CNS tissues of the latter (Roy et

288 al., 2007). These findings led us to speculate that the mechanisms providing RV-specific

289 immune effectors access to CNS tissues fail during infection with SHBRV and possibly other

290 neurotropic viruses (Roy et al., 2007). In this study we have tested the hypothesis with respect

291 to pathogenic RV by comparing the development of peripheral and CNS immunity in mice

292 infected with a variety of RV strains that differ in pathogenicity. The data clearly show that a

293 reduction in the capacity to deliver immune effectors across the BBB into CNS tissues is

294 common to infection with different pathogenic RV isolates. In our survey of infection with

295 diverse RV variants we identified only a single strain, HEP, that does not appear to spread to

296 the CNS of $129 / \mathrm{SvEv}$ mice. We failed to detect viral message or evidence of innate immunity

297 to the virus in CNS tissues from mice infected with HEP, which is considered to be poorly

298 neuroinvasive due to the presence of glutamine at position 333 in its glycoprotein

299 (Dietzschold et al, 1983; Takayama-Ito et al., 2006). Nevertheless, the administration of HEP

300 stimulated a strong RV-specific antibody response. In contrast, all of the other RV strains

301 tested were neuroinvasive as nucleoprotein mRNAs were detectable in the CNS tissues, as

302 were elevations in markers of innate immunity. DRV-4, Thai-DRV, CVS-N2c, CosRV and

303 Skunk RV were lethal for 129/SvEv mice, while similar mice infected with CVS-F3, ERA

304 and PM strains survived. Unlike CVS-F3-infected mice where neurological disease was not

305 seen prior to recovery, 129/SvEv mice infected with ERA and PM exhibited overt

306 neurological signs resembling those of mice lethally infected with DRV-4. On the basis of 
307 these observations we can classify RV into three broad groups: 1/ attenuated viruses that are 308 poorly neuroinvasive (HEP) and a CNS-targeted immune response and changes in BBB 309 permeability are not required for clearance; $2 /$ attenuated neuroinvasive viruses that reach the

310 CNS (ERA, PM, CVS-F3) but are cleared by immune effectors that cross the BBB; and 3/ 311 neuroinvasive, lethal RV where there is no evidence of BBB permeability changes and 312 negligible invasion of immune effectors into CNS tissues (DRV-4, SHBRV, Thai-DRV, 313 CVS-N2c, CosRV, Skunk RV).

314 Adoptive transfer of lymphocytes from 129/SvEv mice lethally infected with SHBRV

315 can clear CVS-F3 from immunodeficient recipients while neither these cells nor similar cells

316 from CVS-F3 - infected donors can clear SHBRV (Roy et al., 2007). We have interpreted

317 these experiments as indicating that some aspect of the SHBRV infection restricts immune 318 effectors from invading CNS tissues (Roy et al., 2007). PLSJL mice, which exhibit a stronger 319 CNS inflammatory response, were found to have an elevated capacity to clear SHBRV (Roy 320 and Hooper, 2007). To provide additional insight into whether or not some aspect of the host 321 response is likely to be a contributing factor in RV infection we compared the outcome of 322 infection with various RV strains in PLSJL and 129/SvEv mice. As previously shown for 323 SHBRV (Roy and Hooper, 2007), DRV-4, CosRV and Skunk RV proved to be less 324 pathogenic in PLSJL mice. In contrast, CVS-N2c and Thai-DRV are highly lethal for both 325 PLSJL and $129 / \mathrm{SvEv}$ mice. The capacity of the virus to replicate and spread likely contributes 326 to the outcome. At 8 days post infection high levels of CVS-N2c nucleoprotein mRNAs are 327 present in the CNS of both infected $129 / \mathrm{SvEv}$ and PLSJL mice but only moderate levels of 328 CosRV nucleoprotein mRNA in the lethally infected 129/SvEv CNS. These are somewhat 329 reduced in the CNS of PLSJL mice that clear the infection, possibly as a consequence of the 
330 initiation of immune-mediated virus clearance. Taken together these results indicate that both

331 host and viral attributes contribute to the lethality of RV infection. In the absence of an

332 effective CNS immune response RV infection is invariably lethal, as is the case for both CVS-

333 N2c and CosRV in 129/SvEv mice. On the other hand, PLSJL mice can survive infection with

334 CosRV but not with the more rapidly replicating CVS-N2c. Conceivably, enhancing the

335 extent of CNS inflammation may have utility in the treatment of RV such as CVS-N2c or

336 Thai-DRV, as has been shown for SHBRV (Roy and Hooper, 2007), but we expect that there

337 is level of infection at which an immune response would no longer be therapeutic.

338 Human rabies is almost always lethal when neurological signs are apparent in the

339 infected host. Since neurological signs are indicative of virus replication inside the CNS

340 tissues, it has generally been considered that once RV has reached the brain it is impossible to

341 clear the virus and the only hope that an individual has of surviving a RV infection is to

342 prevent spread of the virus to the CNS. Thus people who have suffered a probable exposure to

343 a RV are treated by passive administration of pre-formed (exogenous) RV-neutralizing

344 antibodies and by boosting the development of their own (endogenous) RV-specific immunity

345 by vaccination. These treatments, together known as PEP, are thought to act by preventing the

346 spread of RV to the CNS, as they are largely ineffective when given to people who have

347 already manifested neurological signs of rabies (CDC MMWR, 1999). However, this is not

348 always the case. In 2004 a patient survived clinical rabies despite developing neurological

349 signs evidently through the natural development of RV-specific immunity (Willoughby et al.,

350 2005). The appearance of white blood cells, virus specific antibodies and other serum proteins

351 in the cerebrospinal fluid of this individual indicated that the BBB had been breached and that

352 immune effectors likely had access to infected CNS tissues (Willoughby et al., 2005). Our 
353 data comparing 129/SvEv and PLSJL mice suggest that host factors, in particular the capacity

354 to deliver immune effectors across the BBB, play a large role in the ability to survive RV

355 infection. This concept is supported by studies of rabies patients where significant serum RV-

356 specific antibody titers are often present (Kasempimolporn et al., 1991), but immune-

357 mediated changes in the CNS tissues are rare (Murphy, 1977).

358 Human rabies associated with dog and other small carnivores is still a major public

359 health problem in most parts of the world, dog rabies alone killing an estimated 50,000 -

36060,000 people annually (Dressen, 1997; Jackson, 2005). In the United States, around 30,000

361 people receive anti-rabies treatment after being exposed to potentially rabid raccoons and

362 skunks (CDC MMWR, 1999). While there is little objective proof, PEP is generally

363 considered to be effective unless its administration is delayed, as is often the case for lethal

364 infections with SHBRV where exposure to the virus may not be obvious (Messenger et al.,

365 2002). Proper administration of PEP has been known to fail to protect individuals bitten by

366 rabid dogs on the face or other areas that are highly innervated, such as the fingertips (Wilde,

367 2007). In such cases the virus may have reached peripheral nerves quickly after the exposure

368 (Wilde, 2007). Our data would suggest that at some time after the virus has reached the CNS

369 neither PEP nor natural RV-specific immunity can protect an individual because immune

370 effectors are unable to enter the infected CNS tissues. However, we expect that there is a

371 window of time where immune mechanisms can clear RV from the CNS before the infection

372 shuts down the ability to deliver immune effectors into the CNS tissues. In the current study,

373 we found that the RV strains ERA and PM can be cleared from the brain after development of

374 prominent neurological signs of rabies. Our RT-PCR analysis of the CNS tissues confirmed

375 extensive virus replication in the brain during infection with these RV strains. This suggests 
376 that rabies is not invariably lethal if the virus can be cleared before neural damage, either

377 caused by the virus or immunopathology, becomes too extensive. Thus, the predominant

378 direct pathogenic attributes of a RV are likely related to its capacity to replicate and spread

379 through CNS tissues (Dietzschold et al., 1985) as well as alter neuronal structure and function

380 (Scott et al., 2008). We expect that these are in turn dependent upon the loss of the ability to

381 support immune cell invasion across the BBB and limit virus spread. The caveat here is that

382 the early development of CNS immunity is likely to be protective while the late development

383 may be detrimental due to immunopathology consequential to more extensive virus spread.

384 Notably, clear evidence of immunopathology was not seen with any of the RV studied here

385 with the possible exception of ERA where an exaggerated immune response was evident in

$386129 / \mathrm{SvEv}$ mice and one out of 15 animals died while the rest survived with neurological

387 abnormalities.

388 The concept that there is generally an inverse relationship between the pathogenicity

389 of a RV and the capacity of the host to mediate an RV-specific CNS immune response is

390 supported by the fact that there is little evidence of immune cell infiltration into the infected

391 brain tissues of most individuals that succumb to rabies (Murphy, 1977). In a few human

392 rabies cases CNS inflammation has been reported where immunopathology may have

393 contributed to the death (Suja et al., 2004). While this has not been examined in humans, all

394 of the RV strains studied in animal models induce strong innate, pro-inflammatory responses

395 in the CNS as they reach these tissues (Marquette et al., 1996; Wang t al., 2006; Phares et al.,

396 2006; Fig. 3). Moreover, all RV are evidently highly immunogenic with infection inducing

397 RV-specific antibodies in the sera of infected mice (Smith et al., 1982; Wiktor et al, 1977) as

398 well as humans (Kasempimolporn et al., 1991). In addition, RV can evidently be cleared by 
399 immune mechanisms without the immunopathology associated with CNS immune responses

400 to many neurotropic viruses (Miller et al., 1990; Morimoto et al., 1996). Taken together these

401 observations suggest that circumventing the inability of immune effectors to cross the BBB

402 may have therapeutic benefits in people who have developed early signs of rabies. We have

403 previously shown in mouse models that enhancing BBB permeability by the induction of

404 autoimmune CNS inflammation can lead to the clearance of pathogenic RV strains from the

405 brain via naturally developed anti-viral immunity. PLSJL mice, possibly due to an elevated

406 capacity to mediate CNS inflammation, are less likely to die from rabies (Roy and Hooper,

407 2007). These observations not only provide insight into how a rational treatment for rabies

408 may be developed but also how conventional PEP may actually work. It has been well

409 established that passive administration of rabies immunoglobulins (RIG) without active

410 immunization fails to protect RV-infected experimental animals (Hanlon et al., 2002). We

411 speculate that active immunization accelerates the development of RV-specific adaptive

412 immune cells capable of providing immune effectors access to infected neural tissues, a CD4

413 T cell-dependent process (Phares et al., 2007), prior to the loss of the capacity to mediate this

414 process at the BBB. Tailoring a next generation vaccine to target a mechanism that induces

415 functional changes in BBB integrity in a manner that is not susceptible to inhibition may

416 provide a means to survive rabies; if immunopathology can be limited and virus-mediated

417 neuropathology is not extensive or can be reversed.

418

419

420

421 


\section{ACKNOWLEDGEMENTS}

424 We thank Dr. Charles E. Rupprecht and his colleagues at the Center for Disease

425 Control and Prevention, Atlanta, GA and Dr. Bernard Dietzschold of Thomas Jefferson

426 University, Philadelphia, PA for the provision of the virus strains used in this study. We also

427 thank Rhonda B. Kean and Fatu Badiane for helpful contribution to this work. This work was

428 supported by National Institute of Health Grant AI 077033 and AI 060005.

429 


\section{REFERENCES}

431 Abelseth, MK (1964). An attenuated rabies vaccine for domestic animals produced in tissue $432 \quad$ culture. Can Vet J, 5, 279-286.

433 Baer, GM, Bellini, WJ, Fishbein, DB (1990). Rhabdoviruses. B.N. Fields(ed). pp 883-930. $434 \quad$ Virology $2^{\text {nd }}$ edition. Raven Press: New York.

435 Centers for Disease Control and Prevention (1999). Human rabies prevention - United States. 436 Recommendations of the Advisory Committee on immunization practice. MMWR

Centers for Disease Control and Prevention (2007). Human rabies - Indiana and California, 2006. MMWR Morb Mortal Wkly Rep, 56, 361-365.

440 Dietzschold, B, Morimoto, K, Hooper, DC, Smith, JS, Rupprecht, CE, Koprowski, H (2000).

441 Genotypic and phenotypic diversity of rabies virus variants involved in human rabies:

442 implications for postexposure prophylaxis. J Hum Virol, 3, 50-57.

443 Dietzschold, B, Wiktor, TJ, Trojanowski, JQ, Macfarlan, RI, Wunner, WH, Torres-Anjel, MJ, 444 Koprowski, H (1985). Differences in cell-to-cell spread of pathogenic and apathogenic rabies virus in vivo and in vitro. J Virol, 56, 12-8.

446 Dietzschold, B, Wunner, WH, Wiktor, TJ, Lopes, AD, Lafon, M, Smith, CL, Koprowski, H 447 (1983). Characterization of an antigenic determinant of the glycoprotein that correlates with pathogenicity of rabies virus. Proc Natl Acad Sci USA, 80, 70-4.

449 Dressen DW (1997). A global review of rabies vaccine for human use. Vaccine, 15, s2-s6.

$450 \mathrm{Fu}, \mathrm{ZF}$ (1997). Rabies and rabies research: past present and future. Vaccine, 15, s20-s24.

451 Gremliza, L. 1953. Casuistic to the rabies problem. Z Tropenmed Parasitol, 4: 382-389. 
452 Hanlon, CA, Niezgoda, M, Rupprecht, CE (2002). Post exposure prophylaxis for prevention 453 of rabies in dogs. Am J Vet Res, 63(8), 1096-1100.

454 Hattwick, MAW, Weiss, TT, Stechschulte, CJ, Baer, GM, Gregg, MB (1972). Recovery from 455 rabies: a case report. Ann Intern Med, 76: 931-942.

456 Jackson, AC (2005). Recovery from rabies. N Engl J Med, 352, 2549-2550.

457 Jackson, AC, Fenton, MB (2001). Human rabies and bat bites. The Lancet, 357: 1714.

458 Jackson, AC, Reimer, DL, Ludwin. SK (1989). Spontaneous recovery from the 459 encephalomyelitis in mice caused by street rabies virus. Neuropathol Appl Neurobiol, $460 \quad 15,459-475$.

461 Kasempimolporn, S, Hemachudha, T, Khawplod, P, Manatsathit, S (1991). Human immune 462 response to rabies nucleocapsid and glycoprotein antigens. Clin Exp Immunol, 84(2), 463 195-199.

464 Kissi B, Tordo, N, Bourhy, H (1995). Genetic Polymorphism in the Rabies Virus Nucleo465 protein Gene. Virology, 209, 526-537.

466 Marquette, C, Van Dam, AM, Ceccaldi, PE, Weber, P, Haour, F, Tsiang, H (1996). Induction 467 of immunoreactive interleukin-1 beta and tumor necrosis factor-alpha in the brains of 468 rabies virus infected rats. J Neuroimmunol, 68, 45-51.

469 Messenger, SL, Smith, JS, Orciari, LA, Yager, PA, Rupprecht, CE (2003). Emerging pattern 470 of rabies deaths and increased viral infectivity. Emerg Infect Dis, 9, 151-4.

471 Messenger, SL, Smith, JS, Rupprecht, CE (2002). Emerging epidemiology of bat-associated 472 cryptic cases of rabies in humans in the United States. Clin Infect Dis, 35, 738-47.

473 Miller, SD, Gerety, SJ, Kennedy, MK, Peterson, JD, Trotter, JL, Tuohy, VK, Waltenbaugh, C, 474 Dal Canto, MC, Lipton, HL (1990). Class II-restricted T cell responses in Theiler's 
murine encephalomyelitis virus (TMEV)-induced demyelinating disease. III. Failure of neuroantigen-specific immune tolerance to affect the clinical course of demyelination. J Neuroimmuno, 26, 9-23.

Morimoto, K, Hooper, DC, Bornhorst, A, Corisdeo, S, Bette, M, Fu, ZF, Schäfer, MK, Koprowski, H, Weihe, E, Dietzschold, B (1996). Intrinsic responses to Borna disease virus infection of the central nervous system. Proc Natl Acad Sci USA, 93, 13345-50.

Morimoto, K, Hooper, DC, Spitsin, S, Koprowski, H, Dietzschold, B (1999). Pathogenicity of different rabies virus variants inversely correlates with apoptosis and rabies virus glycoprotein expression in infected primary neuron cultures. J Virol, 73, 510-8.

Murphy, FA (1977). Rabies pathogenesis. Arch Virol, 54, 279-297.

Phares, TW, Fabis, MJ, Brimer, CM, Kean, RB, Hooper, DC (2007). A peroxynitritedependent pathway is responsible for blood-brain barrier permeability changes during a CNS inflammatory response; TNF- $\alpha$ is neither necessary nor sufficient. J Immunol, $178,7334-43$.

Phares, TW, Kean, RB, Mikheeva, T, Hooper, DC (2006). Regional differences in bloodbrain barrier permeability changes and inflammation in the apathogenic clearance of virus from the central nervous system. J Immunol, 176, 7666-75.

Roy, A, Hooper, DC (2007). Lethal silver-haired bat rabies virus infection can be prevented by opening the blood-brain barrier. J Virol, 81(15), 7993-7998.

Roy, A, Phares, TW, Koprowski, H, Hooper, DC (2007). Failure to open the blood-brain barrier and deliver immune effectors to the CNS tissues leads to the lethal outcome of Silver-haired bat rabies virus infection. J Virol, 81(3), 1110-1118. 
497 Rupprecht, CE, Dietzschold, B, Campbell, JB, Charlton, KM, Koprowski, H (1992). 498 Consideration of inactivated rabies vaccines as oral immunogens of wild carnivores. $\mathbf{J}$ $499 \quad$ Wildl Dis, 28(4), 629-35.

500 Rupprecht, CE, Glickman, LT, Spencer, PA, Wiktor, TJ (1987). Epidemiology of rabies virus 501 variants. Differentiation using monoclonal antibodies and discriminant analysis. Am J Epidemiol, 126(2), 298-309.

503

504

505

506

507

508

509

510

511

512

513

514

515

516

517

518

519

Scott, CA, Rossiter, JP, Andrew, RD, Jackson, AC (2008). Structural abnormalities in neurons are sufficient to explain the clinical disease and fatal outcome in experimental rabies in yellow fluorescent protein-expressing transgenic mice. J Virol, 82(1), 51321.

Smith, JS, McClelland, CL, Reid, FL, Baer, GM (1982). Dual role of the immune response in street rabies virus infection of mice. Infect Immun, 35(1), 213-221.

Suja, MS, Mahadevan, A, Sundaram, C, Mani, J, Sagar, BC, Hemachudha, T, Wacharapluesadee, S, Madhusudana, SN, Shankar, SK (2004). Rabies encephalitis following fox bite--histological and immunohistochemical evaluation of lesions caused by virus. Clin Neuropathol, 23, 271-6.

Takayama-Ito, M, Inoue, K, Shoji, Y, Inoue, S, Iijima, T, Sakai, T, Kurane, I, Morimoto, K (2006). A highly attenuated rabies virus HEP-Flury strain reverts to virulent by single amino acid substitution to arginine at position 333 in glycoprotein. Virus Res, 119, 208-15.

Wang, ZW, Sarmento, L, Wang, Y, Li, X, Dhingra, V, Tseggai, T, Jiang, B, Fu, ZF (2005). Attenuated rabies virus activates, while pathogenic rabies virus evades, the host innate immune responses in the central nervous system. J Virol, 79(19), 12554-12565. 
520 Wiktor, TJ, Doherty, PC, Koprowski, H (1977). Suppression of cell-mediated immunity by $521 \quad$ street rabies virus. J Exp Med, 145, 1617-1622.

522 Wilde, H (2007). Failures of post exposure prophylaxis. Vaccine, 25, 7605-7609.

523 Willoughby, RE, Tieves, KS, Hoffman, GM, Ghanayem, NS, Amelie-Lefond, CM, Schwabe, 524 MJ, Chusid, MJ, Rupprecht, CE (2005). Brief report: survival after treatment of rabies with induction of coma. N Engl J Med, 352, 2508-2514.

526

527 
530 Table 1. Different strains of RV used for infection.

\begin{tabular}{|c|c|c|c|c|}
\hline RV Strains & $\begin{array}{l}\text { Species } \\
\text { of origin }\end{array}$ & $\begin{array}{l}\text { Passage in the } \\
\text { laboratory }\end{array}$ & $\begin{array}{c}\text { Amounts of } \\
\text { virus in the } \\
\text { inoculum } \\
{\text { (f.f.u })^{\mathrm{a}}}\end{array}$ & References \\
\hline $\begin{array}{l}\text { CVS-F3 (challenge virus } \\
\text { standard, escape mutant) }\end{array}$ & Dog & Cell culture & $1 \times 10^{5}$ & Dietzschold et al., 1983 \\
\hline $\begin{array}{l}\text { ERA (Evelyn Rokitnicki } \\
\text { Abelseth) }\end{array}$ & Dog & Cell culture & $1 \times 10^{5}$ & Abelseth, 1964 \\
\hline PM (Pittman Moore) & Dog & Cell culture & $1 \times 10^{5}$ & Rupprecht et al., 1992 \\
\hline $\begin{array}{l}\text { HEP (high egg passage - } \\
\text { flurry) }\end{array}$ & Dog & Cell culture & $1 \times 10^{5}$ & Takayama-Ito et al., 2006 \\
\hline $\begin{array}{l}\text { SHBRV (silver haired bat- } \\
\text { associated rabies virus) }\end{array}$ & Bat & $\begin{array}{l}\text { Neonatal mouse } \\
\text { brain }\end{array}$ & $1 \times 10^{4}$ & Dietzschold et al., 2000 \\
\hline DRV-4 (dog rabies virus) & Dog & $\begin{array}{l}\text { Neonatal mouse } \\
\text { brain }\end{array}$ & $1 \times 10^{3}$ & Dietzschold et al., 2000 \\
\hline $\begin{array}{l}\text { Thai-DRV (Thai- dog } \\
\text { rabies virus) }\end{array}$ & Dog & $\begin{array}{l}\text { Neonatal mouse } \\
\text { brain }\end{array}$ & $1 \times 10^{5}$ & Dietzschold et al., 2000 \\
\hline $\begin{array}{c}\text { CVS-N2c (challenge virus } \\
\text { standard) }\end{array}$ & Dog & $\begin{array}{l}\text { Neonatal mouse } \\
\text { brain }^{\mathrm{b}}\end{array}$ & $1 \times 10^{5}$ & Morimoto et al., 1999 \\
\hline $\begin{array}{l}\text { CosRV (Coyote rabies } \\
\text { virus) }\end{array}$ & Coyote & $\begin{array}{l}\text { Neonatal mouse } \\
\text { brain }\end{array}$ & $1 \times 10^{4}$ & Dietzschold et al., 2000 \\
\hline Skunk RV & Skunk & $\begin{array}{c}\text { Neonatal mouse } \\
\text { brain }\end{array}$ & $1 \times 10^{4}$ & Rupprecht et al., 1987 \\
\hline
\end{tabular}

531

$532{ }^{a}$ The number of foci developed in 20 hours of in-vitro cultured monolayer of baby hamster

533 kidney (BHK) cells was counted as a measure of live virus particles in the inoculum.

534 b CVS-N2c was cloned in cell culture from parental CVS-24 strain, and then continued to 535 passage in neonatal mouse brain.

536

537 
539 Table 2. Survival of mice following infection with different RV strains ${ }^{\mathrm{a}}$.

\begin{tabular}{|c|c|c|c|c|c|c|}
\hline \multirow{2}{*}{$\begin{array}{l}\text { Virus } \\
\text { Strains }\end{array}$} & \multicolumn{3}{|c|}{ 129/SvEv } & \multicolumn{3}{|c|}{ PLSJL } \\
\hline & Mortality $^{\text {b }}$ & $\begin{array}{c}\text { Clinical } \\
\text { signs }\end{array}$ & $\begin{array}{c}\% \\
\text { Survival }\end{array}$ & Mortality & $\begin{array}{c}\text { Clinical } \\
\text { signs }\end{array}$ & $\begin{array}{c}\% \\
\text { Survival }\end{array}$ \\
\hline CVS-F3 & $0 / 20$ & $\begin{array}{l}\text { Piloerection, } \\
\text { weight loss }\end{array}$ & 100 & $0 / 10$ & \multirow{4}{*}{ None } & 100 \\
\hline ERA & $1 / 15$ & \multirow{3}{*}{$\begin{array}{l}\text { Piloerection, } \\
\text { weight loss, } \\
\text { hunched back, } \\
\text { ataxia }^{c}\end{array}$} & 93 & $0 / 20$ & & 100 \\
\hline $\mathbf{P M}$ & $0 / 15$ & & 100 & $0 / 10$ & & 100 \\
\hline DRV-4 & $10 / 10$ & & 0 & $0 / 10$ & & 100 \\
\hline SHBRV & $20 / 20$ & \multirow{3}{*}{$\begin{array}{l}\text { Piloerection, } \\
\text { weight loss, } \\
\text { sudden onsets } \\
\text { of severe } \\
\text { agitation, } \\
\text { vellication, } \\
\text { ataxia, apnea }\end{array}$} & 0 & $12 / 20$ & \multirow{3}{*}{$\begin{array}{c}\text { Dying: } \\
\text { piloerection, } \\
\text { weight loss, } \\
\text { hunched back, } \\
\text { apnea, } \\
\text { vellication } \\
\text { Surviving: no } \\
\text { clinical sign }\end{array}$} & 40 \\
\hline $\begin{array}{l}\text { Thai- } \\
\text { DRV }\end{array}$ & $15 / 15$ & & 0 & $15 / 17$ & & 11 \\
\hline CVS-N2c & $20 / 20$ & & 0 & $18 / 20$ & & 10 \\
\hline CosRV & $10 / 10$ & \multirow{2}{*}{$\begin{array}{l}\text { Dying: weight } \\
\text { loss, ataxia, } \\
\text { piloerection } \\
\text { Surviving: } \\
\text { none }\end{array}$} & 0 & $1 / 20$ & \multirow{2}{*}{$\begin{array}{c}\text { Dying: } \\
\text { piloerection, } \\
\text { weight loss, } \\
\text { ataxia } \\
\text { Surviving: } \\
\text { none } \\
\end{array}$} & 95 \\
\hline $\begin{array}{c}\text { Skunk } \\
\text { RV }\end{array}$ & $9 / 10$ & & 10 & $1 / 10$ & & 90 \\
\hline HEP & $0 / 15$ & None & 100 & $0 / 10$ & None & 100 \\
\hline
\end{tabular}

540

541 a Two strains of mice were infected with different RV strains as described in the Materials

542 and Methods and observed for clinical signs and mortality for a period of 30 days.

543 b Number of mice that died over total number of mice used to monitor survival following an 544 infection.

$545{ }^{c}$ Clinical signs in 129/SvEv mice infected with ERA and PM begin to show 8-10 days post

546 infection and stay for 8-10 more days. Mice infected with DRV-4 show similar signs but die 547 within 3-4 days of the first appearance of clinical rabies. 
549 Figure 1. Detection of nucleoprotein message in the CNS of mice infected with different

550 RV strains. RV nucleoprotein mRNA expression was detected in the CNS tissues (cerebral

551 cortex and cerebellum) of mice infected with different RV strains 8 days previously, by RT-

552 PCR as described in Materials and Methods. Results of 4 randomly chosen mice (numbered 1,

$5532,3,4)$ from each group of 10 mice are shown. 129/SvEv mice were infected with various RV strains listed in Table 1, via intra dermal injection as described in Materials and Methods. Mice were monitored for morbidity and mortality for 30 days. First 20 days observation is shown in the graph, there were no more deaths in any of the groups between 20 to 30 days post infection.

561 Figure 3. Innate immune response in the cerebellar tissues following infection with

562 different RV strains. Mice were infected with different RV strains as described in Materials

563 and Methods. Eight days after infection, cerebellar tissues were collected and levels of

564 mRNAs specific for TNF- $\alpha$ and IL-6 genes were measured using QRT-PCR as described in

565 Materials and Methods. The levels of mRNA in each sample were normalized to the level of

566 L13 gene expression in those samples and are expressed as the fold-increase over the

567 expression levels detected in samples from uninfected control animals. Statistically significant

568 differences in gene expression between infected and uninfected mice were calculated using

569 Mann-Whitney test and are denoted by the symbol $*(p<0.01, \mathrm{n}=10$ in each group). 
571 Figure 4. Serum anti-RV antibody titers of the mice infected with different RV strains.

572 Sera were collected from the uninfected and infected mice ( $\mathrm{n}=10$ per group) described in the

573 legend of Fig 3 and the amounts of RV-specific IgG molecules were measured using ELISA

574 as described in Materials and Methods. Antibody titer in the Y-axis is the inverse of the

575 dilution of a serum sample corresponding to the half of the maximum absorbance detected in

576 that sample. Statistically significant ( $t$-test comparison with non-immune sera) levels of RV-

577 specific antibody titers are seen in the sera of all infected mice.

579 Figure 5. Accumulation of immune cells in the cerebellar tissues following infection with

580 different RV strains. Levels of mRNAs specific for CD4, $\kappa$-light chain ( $\kappa-L C)$ and CD19

581 genes were quantified using QRT-PCR in the total RNA isolated from the cerebellum of

582 uninfected and infected mice described in the legend of Fig 3 and normalized to L13 gene

583 expression in those samples as described in Materials and Methods. Levels of gene expression

584 are represented as the fold-increase in mRNA copy numbers over normalized copies in

585 samples from uninfected control animals as described in Materials and Methods. Statistically

586 significant differences in gene expression between infected and uninfected mice were

587 calculated using Mann-Whitney test and are denoted by the symbol $* * p<0.01(\mathrm{n}=10)$.

588

589 Figure 6. BBB permeability changes in the cerebellum of the mice infected with different

590 RV strains. BBB permeability was assessed by measuring the leakage of Na-fluorescein from

591 the circulation into the cerebellum 8 days after RV infection and are expressed as the fold-

592 increase in Na-fluorescein uptake by the CNS tissues of RV infected mice over that of

593 uninfected mice, as described in Materials and Methods. The dotted line represents the BBB 
594 permeability in uninfected mice. Statistical significance of the differences in permeability

595 between infected and uninfected mice was calculated using Mann-Whitney test and are

596 denoted by the symbol $* * p<0.01, * * * p<0.001(\mathrm{n}=10)$.

597

598 Figure 7. Nucleoprotein message levels in the cerebellar tissues of 129/SvEv and PLSJL 599 mice infected with CosRV and CVS-N2c RV strains. Eight days post infection QRT-PCR

600 was used to quantify the levels of mRNAs specific for RV-nucleoprotein in total RNA 601 isolated from the cerebellar tissues of mice infected with CosRV and CVS-N2c RV strains 602 ( $\mathrm{n}=5$ per group). Levels normalized to L13 gene expression in the samples, as described in 603 Materials and Methods, are presented. Significantly higher levels of nucleoprotein mRNA in 604 CVS-N2c by comparison with CosRV infected mice are denoted by $*$ ( $p<0.05, t$-test). 605 Significantly lower levels of nucleoprotein mRNA in PLSJL mice by comparison with $606 \quad 129 / \mathrm{SvEv}$ mice are denoted by \# $(p<0.05, t$-test $)$.

607

608

609 
611 FIGURE 1.

612

613

614

615

616

617

618

619

620

621

622

623

Cortex Cerebellum

5

\begin{tabular}{|c|c|c|c|c|c|c|c|c|}
\hline & \multicolumn{4}{|c|}{ Cortex } & \multicolumn{4}{|c|}{ Cerebellum } \\
\hline & 1 & 2 & 3 & 4 & 1 & 2 & 3 & 4 \\
\hline ERA & $\square$ & $\square$ & 0 & $\square$ & $\square$ & $\square$ & 미 & $\square$ \\
\hline PM & 0 & $\square$ & $\square$ & $\square$ & 口 & $\square$ & 0 & 口 \\
\hline DRV-4 & $\theta$ & $\square$ & 0 & $\square$ & E & & & E \\
\hline Thai-DRV & $x$ & ㅁ & $\infty$ & $\omega$ & $x=$ & 口 & 0 & \\
\hline CVS-N2c & $\theta$ & $\theta$ & $\theta$ & $\theta$ & ש & E & $\theta$ & E \\
\hline CosRV & $\theta$ & $\square$ & $\square$ & $\theta$ & $\theta$ & $\theta$ & $E$ & \\
\hline SkunkRV & E & $\mathrm{ne}$ & $\mathbf{n}$ & $\theta$ & & $E$ & & \\
\hline SHBRV & $\theta$ & $\theta$ & $E$ & $\theta$ & $\theta$ & E & & \\
\hline CVS-F3 & tis & $\theta$ & H & $\theta$ & $\mathrm{E}$ & 10 & H & E \\
\hline HEP & & & & & & & & \\
\hline
\end{tabular}

624

625

626

627

628

629

630

631

632 


\section{FIGURE 2.}

635

636

637

638

639

640

641

642

643

644

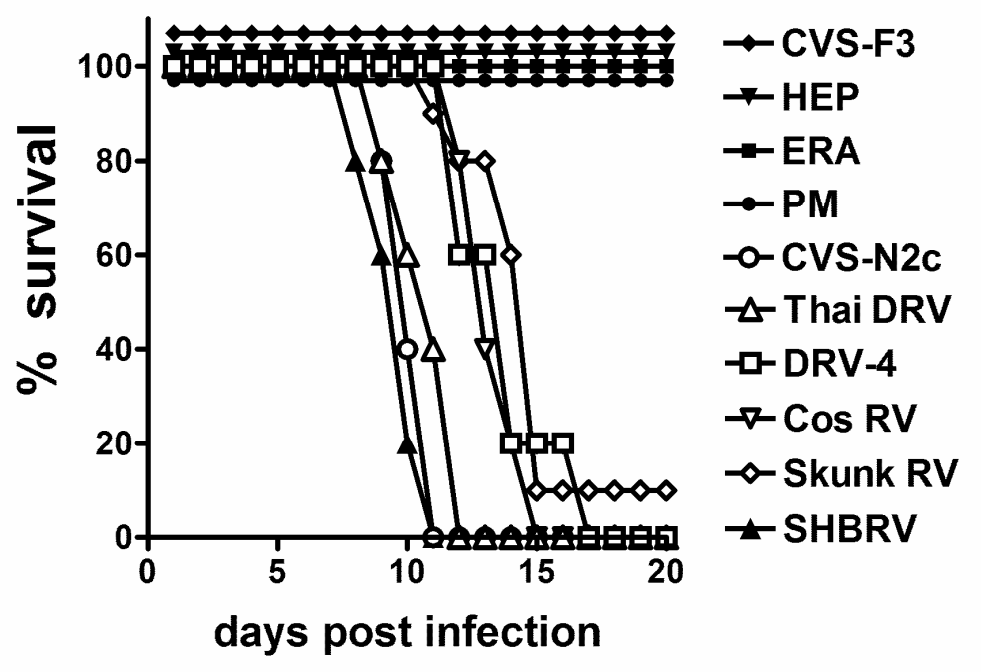

645

646

647

648

649

650

651

652

653

654

655 


\section{$657 \quad$ FIGURE 3.}

658

659

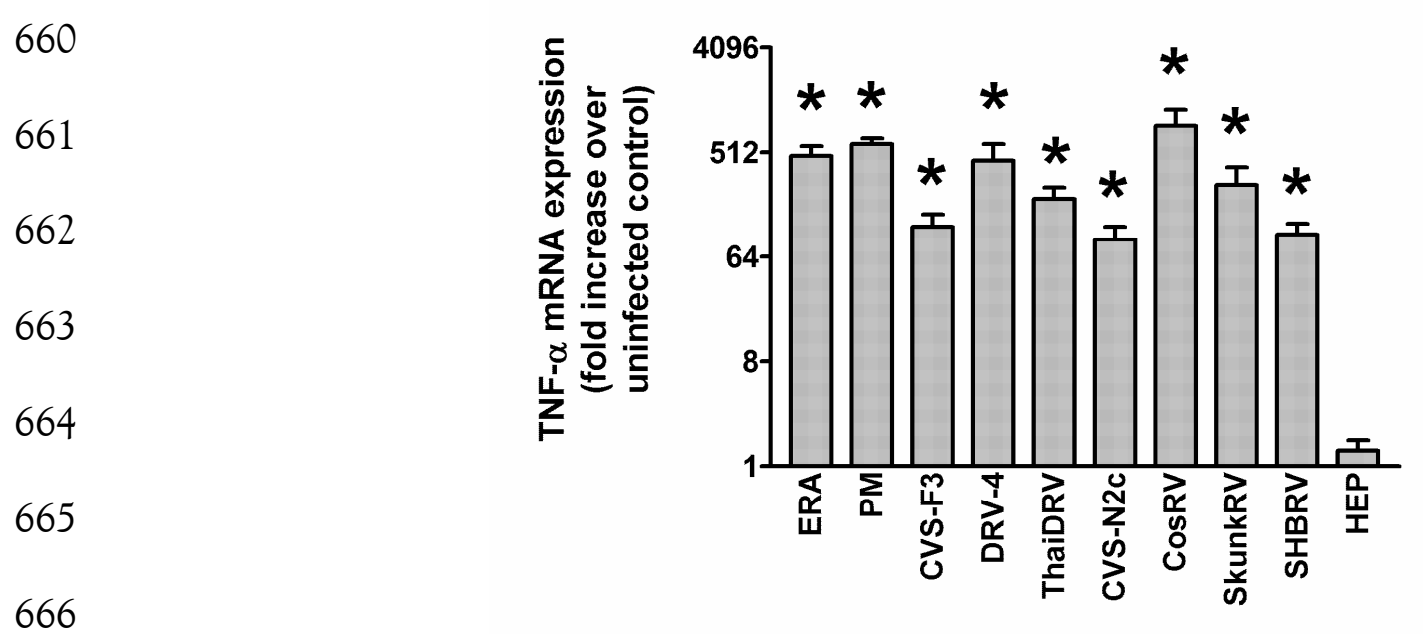

667

668

669

670

671

672

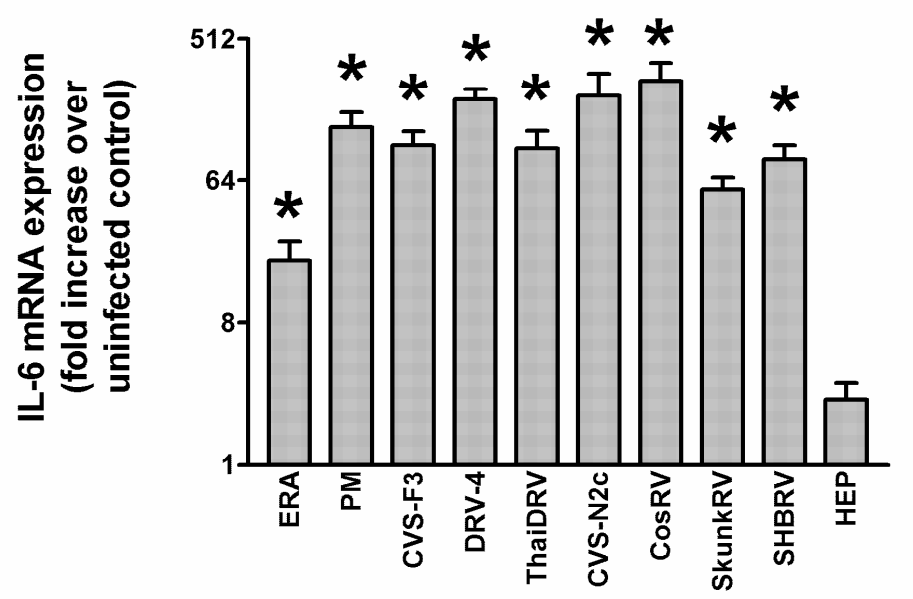

673

674

675

676

677

678 
680 FIGURE 4.

681

682

683

684

685

686

687

688

689

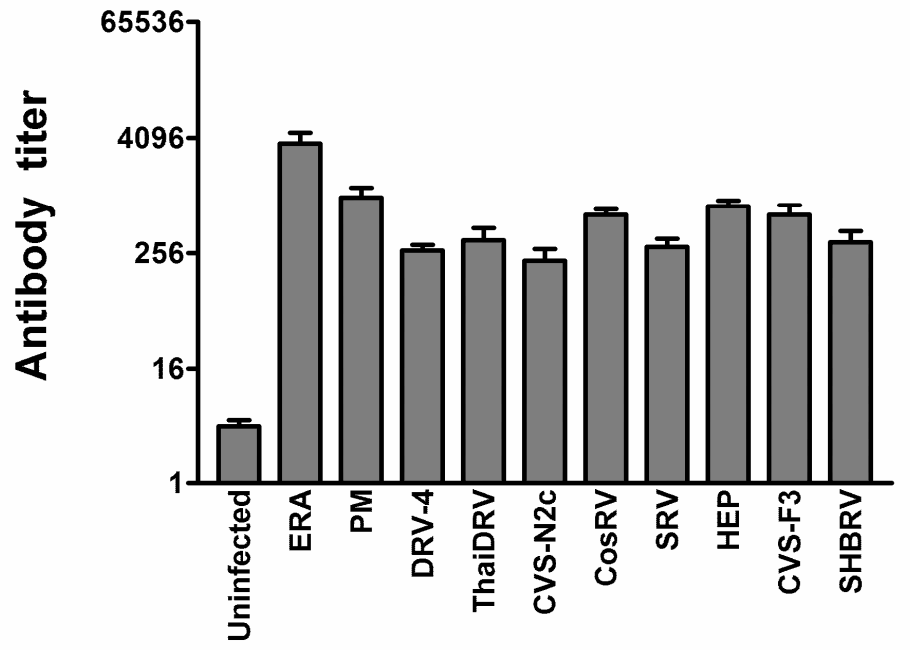

690

691

692

693

694

695

696

697

698

699

700

701 
703 FIGURE 5.

704

705

706

707

708

709

710

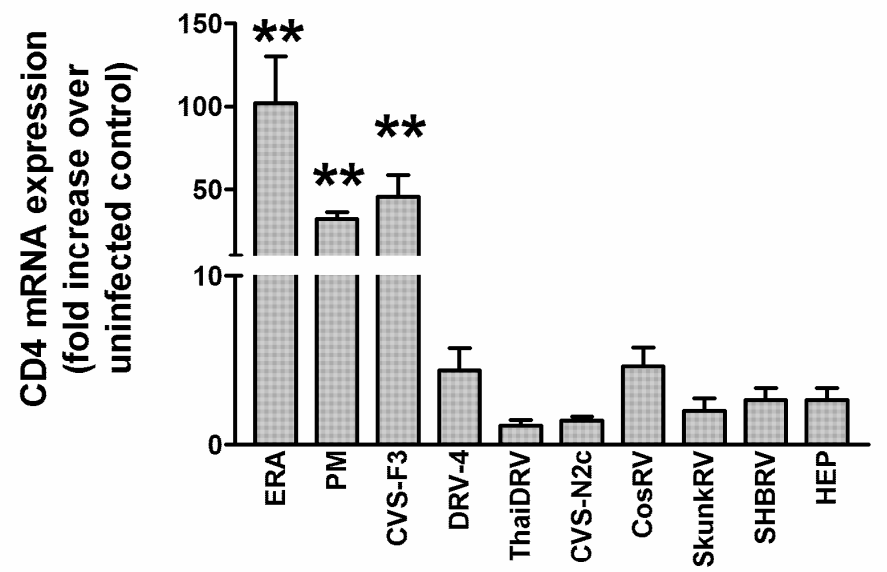

711

712

713

714

715

716

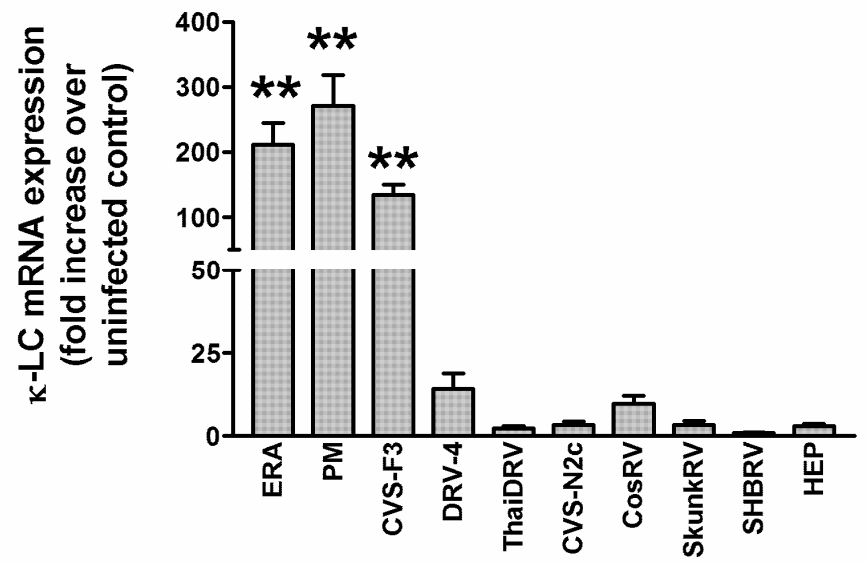

717

718

719

720

721

722

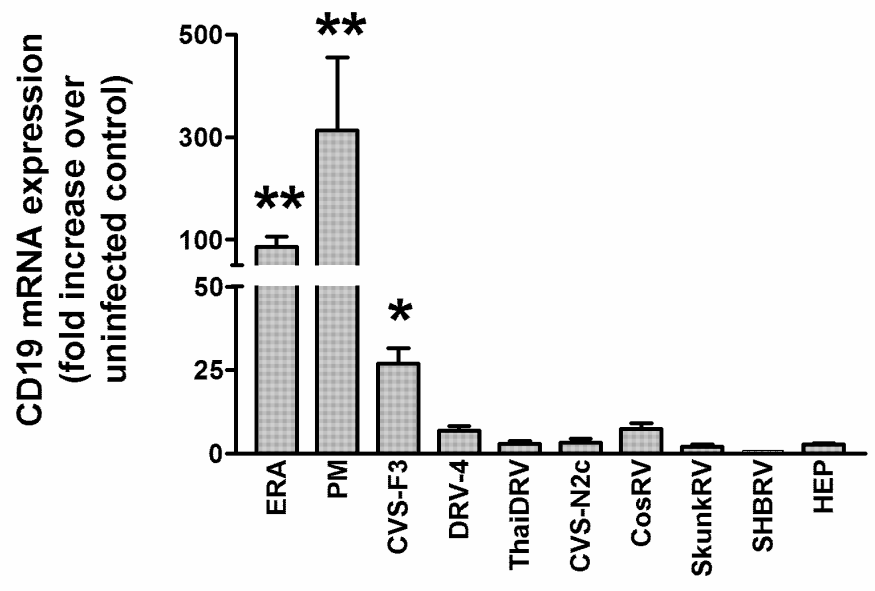

723 
726 FIGURE 6.

727

728

729

730

731

732

733

734

735

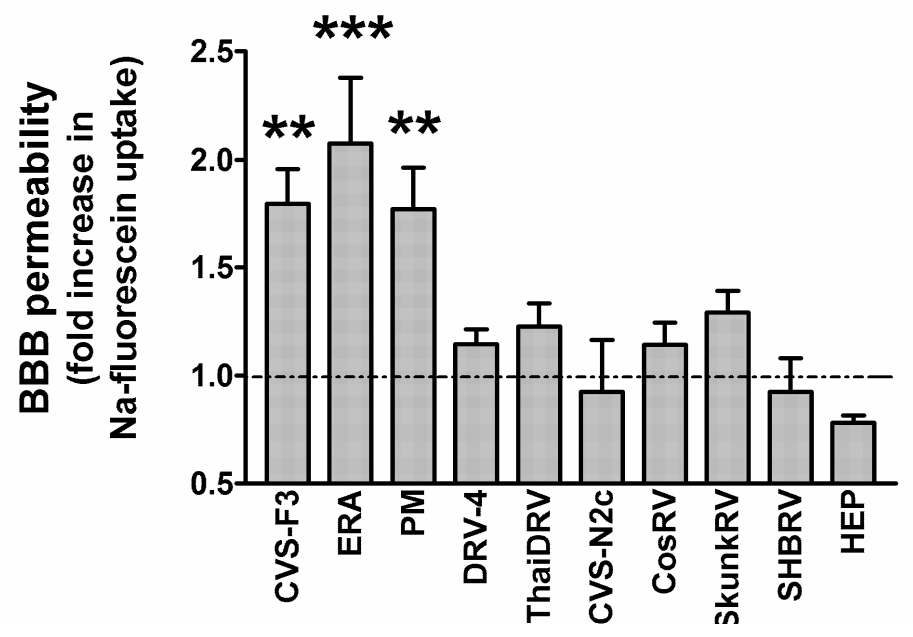

736

737

738

739

740

741

742

743

744

745

746

747 
749 FIGURE 7.

750

751

752

753

754

755

756

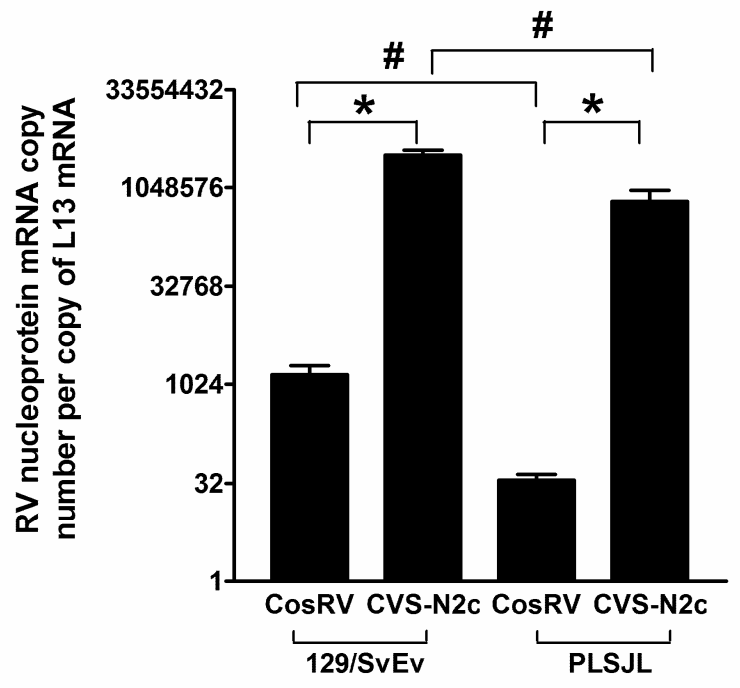

758

759

760 